\title{
Pleural-fluid myeloperoxidase in complicated and noncomplicated parapneumonic pleural effusions
}

\author{
J. Alegre*, J. Jufresa*, R. Segura\#, A. Ferrer ${ }^{\mp}$, L. Armadans ${ }^{+}$, C. Aleman*, R. Marti", \\ E. Ruiz*, T. Fernández de Sevilla*
}

Pleural-fluid myeloperoxidase in complicated and noncomplicated parapneumonic pleural effusions. J. Alegre, J. Jufresa, R. Segura, A. Ferrer, L. Armadans, C. Aleman, R. Marti, E. Ruiz, T. Fernández de Sevilla. C) ERS Journals Ltd 2002.

ABSTRACT: The diagnostic accuracy of myeloperoxidase (MPO) in pleural fluid, for differentiating between complicated and noncomplicated parapneumonic pleural effusions (PPE) evaluated prospectively.

Seventy patients aged $>18$ yrs with PPE (36 complicated and 34 noncomplicated) were studied after admission to a tertiary referral teaching hospital. MPO concentration was measured in plasma and pleural fluid using a double-antibody competitive radioimmunoassay.

The concentrations of MPO in complicated and noncomplicated PPE were compared using a Mann-Whitney U-test and multiple logistic regression models were used to predict the odds that an effusion was complicated. MPO pleural-fluid concentrations were significantly higher in complicated than in noncomplicated PPE. After excluding purulent effusions, pleural-fluid MPO was the marker that best differentiated between the two types of PPE: the area under the receiver operating characteristic curve was 0.912, the sensitivity was $87.5 \%$ and the specificity was $85.1 \%$ at a cut-point limit of $3.000 \mu \mathrm{g} \cdot \mathrm{L}^{-1}$.

The authors concluded that the concentration of pleural-fluid myeloperoxidase helps to differentiate between nonpurulent complicated and noncomplicated parapneumonic pleural effusions.

Eur Respir J 2002; 19: 320-325.

\author{
Depts of *Internal Medicine, ${ }^{\#}$ Bio- \\ chemistry, "Microbiology, ${ }^{+}$Preventive \\ Medicine and Epidemiology, Vall \\ d'Hebron General Hospital, Barcelona, \\ Spain.
}

\author{
Correspondence: J. Alegre \\ Juan de Garay $19,3^{\circ} 1^{\mathrm{a}}$ \\ 08041, Barcelona \\ Spain \\ Fax: 3432844234 \\ E-mail:18502jam@comb.es
}

Keywords: Myeloperoxidase parapneumonic pleural effusions

Received: June 132000

Accepted after revision September 5 2001

This work was financed in part by a Fondo de Investigacion Sanitaria grant (96/0977).
Parapneumonic pleural effusions (PPE) are found in $20-75 \%$ of patients hospitalized with moderate-tosevere community-acquired pneumonia [1]. The formation of a PPE consists of three stages: exudative, fibrinopurulent and fibrous [2]. The clinical consequences of this evolution allow PPE to be divided into complicated and noncomplicated types. Therefore, PPE is not a single entity, but represents a progression in which purulent, complicated PPE is the final stage [3]. These parapneumonic effusions are a challenge to clinicians attempting to determine whether the effusion will respond to antibiotic therapy alone or whether the patient requires pleural drainage to manage an established empyema or prevent an empyema from forming. Proper assessment is vital because failure to initiate prompt and effective drainage when indicated increases the morbidity rates associated with pulmonary infection [4]. It is important, therefore, to discriminate as accurately and as early as possible between patients with parapneumonic effusions who are likely to respond to antibiotics alone and those who require pleural-fluid drainage [5].

It is widely accepted that polymorphonuclear cells play a key role in the acute inflammatory response to bacterial infection. Neutrophils participate in the inflammatory response through the release of peptides and proteases [6]. Polymorphonuclear elastase (PMNE), a protease that originates from azurophil granules of the polymorphonuclear leukocytes (neutrophils) in response to the release of inflammatory mediators, stands out among these [7]. The value of pleuralfluid PMN-E in the differentiation between infective and noninfective effusions has recently been established [8]. Myeloperoxidase (MPO) is a protein responsible for the peroxidase activity characteristic of the azurophilic granules and is essential for the oxidative mechanism of the phagocytes. MPO and reduced nicotinamide-adenine dinucleotide phosphate (NADP-H) oxidase are the main proteins that participate in oxidative-type microbicidal activity [9]. Increased concentrations of MPO have been reported in various inflammatory processes [10-12]. The authors previously detected higher levels of pleuralfluid MPO in complicated bacterial effusions than in noninfective effusions [13].

The criteria currently used for pleural drainage in the treatment of PPE are based on findings such as acid $\mathrm{pH}$ and purulent-appearing fluid, signs of an already advanced phase of infection [14, 15]. Measurements of $\mathrm{pH}$ are, however, dependant on the mode of sample carriage and delay in measurement [16]. A fluid glucose value $<40 \mathrm{mg} \cdot \mathrm{dL}^{-1}$ or a located hydogenase $(\mathrm{LDH})$ value $>1,000 \mathrm{IU} \cdot \mathrm{L}^{-1}$ has also been 
used in the early diagnosis of complicated PPE [3], although the development of pleural thickening in the evolution of complicated PPE is not unusual [17, 18]. In view of the persistence of local complications a prospective study, to evaluate whether pleural-fluid MPO concentration might be useful for early differentiation between complicated and noncomplicated PPE, was performed.

\section{Patients and methods}

\section{Study population and diagnostic criteria}

The study included patients aged $>18$ yrs with PPE admitted consecutively to a general teaching hospital. Patients were divided into two groups. 1) Complicated parapneumonic, according to at least one of the following criteria: macroscopic pus, presence of organisms on Gram-stain or culture, fluid $\mathrm{pH}<7.2$ with normal peripheral blood $\mathrm{pH}$, or fluid glucose concentrations $<40 \mathrm{mg} \cdot \mathrm{dL}^{-1}$. 2) Noncomplicated parapneumonic, according to at least one of the following criteria: pleural effusion associated with a nonpurulent pleural fluid; negative fluid microbiological studies; fluid $\mathrm{pH}>7.2$ with normal peripheral blood $\mathrm{pH}$; or fluid glucose $>40 \mathrm{mg} \cdot \mathrm{dL}^{-1}$.

Seventy patients with PPE were enrolled in the study. Thirty-six had complicated PPE (51.5\%) and the remaining 34 had noncomplicated PPE (48.5\%). Of the patients with complicated PPE (mean age 56 yrs, $89 \%$ males), $21(58 \%)$ had positive cultures and $20(55 \%)$ purulent pleural effusion. Sixty-seven per cent had other illnesses (chronic bronchitis, diabetes mellitus or chronic hepatic disease) and $28 \%$ had received antibiotics previously. The most frequently used antibiotic during hospitalization was co-amoxyclavulanic acid. All the patients with complicated PPE were treated by pleural drainage, six received intrapleural urokinase and three had pleural decortication. Complications consisting of pleural thickening and pleural loculation were recorded in 31 patients $(86 \%)$.

The 34 patients with noncomplicated PPE had a mean age of 54 yrs and $70.5 \%$ were males. In $59 \%$, other illnesses were present (chronic bronchitis, diabetes mellitus, chronic hepatic disease) and 35\% had received antibiotics previously. During hospitalization, the most frequently used antibiotic combinations $(88 \%)$ were cephalosporins plus macrolides. Complications, including loculations and pleural thickening, were present in $35 \%$ of patients. None of the patients were taking either corticosteroids or nonsteroidal anti-inflammatory drugs.

\section{Biochemical, cytological and bacteriological methods}

Biochemical measurements were carried out using a Hitachi 919 automatic analyser (Boehriger Mannheim, $\mathrm{GMbH}$, Mannheim, Germany), using the method of Biuret for proteins, hexokinase for glucose, and pyruvate-to-lactate reduction at $37^{\circ}$ for $\mathrm{LDH}$.

For determination, $\mathrm{pH}$ pleural fluid was collected directly into a heparinized blood-gas syringe and was maintained anaerobically. The syringe containing the pleural fluid was immediately placed on ice and transferred to the laboratory. Pleural-fluid $\mathrm{pH}$ was measured within 20 min after thoracocentesis using a selective $\mathrm{pH}$ electrode (Chiron Diagnostics 860; Ciba Corning Diagnostics Corp., Medfield, MA, USA).

For PMN-E and MPO determinations, samples were collected in ethylene diamine tetra-acetic acid and plasma or pleural-fluid supernatants were separated within the first hour. PMN-E was determined by an immunoactivation method (IMAC, Merck $\mathrm{kGaA}$, Darmstad, Germany) that measures free and $\alpha_{1}$ proteinase inhibitor-bound PMN-E ${ }^{19}$. The between-run imprecision for a mean value of $134 \mu \mathrm{g} \cdot \mathrm{L}^{-1}$ was $8.9 \% \quad(\mathrm{n}=20)$. MPO was measured by double-antibody competitive radioimmunoassay (Pharmacia Diagnostics, Uppsala, Sweden). The between-run imprecision for a mean value of $450 \mathrm{mg} \cdot \mathrm{L}^{-1}$ was $4.8 \%(\mathrm{n}=20)$. Lysozyme was measured by means of a turbidimetric method.

Total white blood cell counts were carried out with a Coulter $(\mathbb{R})$-s-Plus IV Counter Izasa, Spain. To differentiate between leukocytes, the sample was

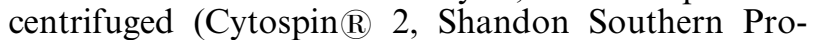
ducts Ltd, UK) at 2,000 revolutions per minute for $8 \mathrm{~min}$, and the preparation obtained was stained with May-Grunwald-Giemsa.

For microbiological studies, pleural-fluid samples were extracted by thoracocentesis under aseptic conditions and sent to the bacteriology laboratory in a sterile tube and an anaerobic blood culture vial (Bactec NR 660 system; Becton Dickinson, USA). Gram and Ziehl-Neelsen stains were carried out and cultures were performed in conventional media for aerobic and anaerobic micro-organisms, fungi, legionella and mycobacteria. Pneumococcal antigen was detected by means of the coagglutination technique (Phedebact Pneumococcus test; Boule Diagnostics, Huddinge, Sweden).

\section{Statistical analysis}

Because of the presence of extreme values among the pleural-fluid biochemical variables, the MannWhitney U-test was used to compare their distribution in complicated and noncomplicated PPE. Multiple logistic regression models were used to predict the odds that an effusion was complicated.

The validity of the predictions derived from the multiple logistic regression models was assessed. Each type of misclassification was evaluated according to its cost (weights were -2 for misclassifying a complicated PPE as noncomplicated, -1 for misclassifying a noncomplicated PPE as complicated, and 0 for correct predictions). The cut-point with the highest global value was selected according to this evaluation. The binomial distribution was used to estimate the $95 \%$ confidence intervals (CI) for sensitivity and specificity. To assess the diagnostic accuracy of MPO as an early marker in the diagnosis of complicated PPE, the statistical analysis was repeated after excluding purulent effusions. 
The agreement between pleural $\mathrm{pH}<7.2$, pleural glucose $<40 \mathrm{mg} \cdot \mathrm{dL}^{-1}$, pleural $\mathrm{LDH}>1,000 \mathrm{IU} \cdot \mathrm{L}^{-1}$ and a pleural MPO value greater than the suggested cutpoint was assessed. The kappa statistic was used to adjust the observed agreement for chance; its standard error was used to test the hypothesis that the underlying value of kappa was zero [20]. This study evaluated whether a difference of 0.3 between plasma and pleural $\mathrm{pH}$ differentiated between complicated and noncomplicated PPE. The Mann-Whitney U-test was used to evaluate the associations between $\mathrm{pH}$, glucose, LDH, MPO or polymorphonuclear leukocyte count in pleural fluid and later loculation of PPE. The study was approved by the Clinical Assay Committee.

\section{Results}

Table 1 shows the medians, 25th and 75th percentiles and ranges for $\mathrm{pH}$, glucose, proteins, $\mathrm{LDH}$, neutrophil count and MPO in peripheral blood in the patients. There were no statistically significant differences between the two groups.

Table 2 summarizes the distribution of the same biochemical variables in pleural fluid. As expected, fluid $\mathrm{pH}$ and glucose values were lower in complicated than in noncomplicated PPE $(\mathrm{p}<0.001)$. Median pleural-fluid MPO values were $98.7 \mu \mathrm{g} \cdot \mathrm{L}^{-1}$ in complicated and $1.7 \mu \mathrm{g} \cdot \mathrm{L}^{-1}$ in noncomplicated PPE $(\mathrm{p}<$ 0.001). LDH pleural-fluid concentrations were also higher in complicated PPE.

Figure 1 shows the logarithm of pleural MPO concentrations in the two types of parapneumonic effusions. The highest MPO values were seen in complicated PPE. When forward stepwise modelling was used to identify the main predictors of complicated PPE among the pleural-fluid variables (proteins, $\log \mathrm{LDH}, \log$ neutrophil count, and $\log$ MPO), the logarithm of MPO concentration was included first (log-likelihood ratio Chi-squared test was equal to 65.656; $\mathrm{p}<0.001$ ) and was followed by $\log \mathrm{LDH}$ (log-likelihood ratio Chi-squared test equal to 4.570; $\mathrm{p}=0.033$ ).

With use of a logistic regression model incorporating the log MPO concentration in pleural fluid, the odds that a PPE was complicated increased with its value (odds ratio (OR): 4.43; 95\% CI: 2.18-8.97). When the log MPO in serum was added to this model, the log-likelihood ratio Chi-squared test was not significant (Chi-squared equal to $1.53 ; \mathrm{p}=0.217$ ). The area under the receiver operating characteristics (ROC) curve for the log pleural-fluid MPO was 0.9690 (fig. 2).

The MPO cut-point for the diagnosis of complicated PPE was $3.000 \mu \mathrm{g} \cdot \mathrm{L}^{-1}$. Sensitivity at this level was $94.1 \%(95 \% \mathrm{CI}$ : 80.3-99.3) and specificity was $85.1 \%$ (68.9-95). A specificity of $91.2 \%$ (75.2-97.7) had a sensitivity of $75 \%$ (47.4-91.7) and a specificity of $97.1 \%(82.9-99.8)$ had a sensitivity of $56 \%(30.6-79.2)$. After excluding purulent PPE from the analysis, the sensitivity of pleural-fluid MPO values equal to or greater than this cut-point was $87.5 \%$ (61.7-98.5) and specificity was $85.1 \%(68.9-95)$. The area under the ROC curve for the logarithm of pleural-fluid MPO was 0.912. (fig. 3). A difference of 0.3 between plasma and pleural $\mathrm{pH}$ had a sensitivity of $77.4 \%$ and a specificity of $100 \%$ in the differentiation between complicated and noncomplicated PPE.

Thirty-eight patients with complicated PPE or pleural $\mathrm{LDH}>1,000 \mathrm{IU} \cdot \mathrm{L}^{-1}$ had pleural-fluid MPO concentrations $>3.000 \mu \mathrm{g} \cdot \mathrm{L}^{-1}$, while 29 patients with noncomplicated PPE and pleural $\mathrm{LDH}<1,000 \mathrm{IU} \cdot \mathrm{L}^{-1}$ had an MPO concentration $<3.000 \mu \mathrm{g} \cdot \mathrm{L}^{-1}$. The observed agreement between the combination of pleural $\mathrm{pH}$, glucose and LDH with pleural MPO in the diagnosis of complicated PPE was $95.7 \%$, the kappa statistic was 0.913 ( $\mathrm{SE}=0.049 ; \mathrm{p}<0.0001)$. After excluding purulent effusions, the concordance between pleural MPO and the combination of

Table 1.-Biochemical and bacteriological variables in peripheral blood

\begin{tabular}{|c|c|c|c|c|c|}
\hline & Minimum & $\mathrm{P}_{25}$ & Median & P75 & Maximum \\
\hline \multicolumn{6}{|l|}{$\mathrm{pH}$} \\
\hline Complicated & 7.30 & 7.35 & 7.38 & 7.42 & 7.5 \\
\hline Noncomplicated & 7.30 & 7.37 & 7.39 & 7.42 & 7.5 \\
\hline \multicolumn{6}{|l|}{ Glucose $\mathrm{mg} \cdot \mathrm{dL}^{-1}$} \\
\hline Complicated & 64 & 90 & 115 & 117 & 388 \\
\hline Noncomplicated & 74 & 93 & 120 & 124 & 274 \\
\hline \multicolumn{6}{|l|}{ Protein $\mathrm{g} \cdot \mathrm{dL}^{-1}$} \\
\hline Complicated & 4.8 & 5.4 & 6.05 & 6.5 & 8.1 \\
\hline Noncomplicated & 5.0 & 5.4 & 6.18 & 6.7 & 7.6 \\
\hline \multicolumn{6}{|l|}{$\mathrm{LDH} \mathrm{IU} \cdot \mathrm{L}^{-1}$} \\
\hline Complicated & 157 & 227 & 312 & 375 & 570 \\
\hline Noncomplicated & 207 & 297 & 450 & 591 & 1.17 \\
\hline \multicolumn{6}{|c|}{ Myeloperoxidase $\mu \mathrm{g} \cdot \mathrm{L}^{-1}$} \\
\hline Complicated & 172 & 390 & 641 & 798 & 2.61 \\
\hline Noncomplicated & 82 & 360 & 604 & 749 & 1.45 \\
\hline \multicolumn{6}{|l|}{ Neutrophils $10^{3} \cdot \mathrm{uL}^{-1}$} \\
\hline Complicated & 4.80 & 5.34 & 10.8 & 14.2 & 36.1 \\
\hline Noncomplicated & 4.50 & 5.24 & 8.33 & 10.1 & 23.1 \\
\hline
\end{tabular}

Complicated: complicated paraneumonic effusion $n=36$; Noncomplicated: Noncomplicated paraneumonic effusion $n=34$; LDH: lactate dehydrogenase; P25: 25th percentile; P75: 75th percentile; No significant differences between types of effusion. 
Table 2. - Biochemical and bacteriological variables in pleural fluid

\begin{tabular}{|c|c|c|c|c|c|c|}
\hline & Minimum & $\mathrm{P} 25$ & Median & P75 & Maximum & p-value \\
\hline \multicolumn{7}{|l|}{$\mathrm{pH}$} \\
\hline Complicated & 5.5 & 6.53 & 6.70 & 7.07 & 7.39 & \\
\hline Noncomplicated & 7.30 & 7.37 & 7.43 & 7.50 & 7.61 & $<0.001$ \\
\hline \multicolumn{7}{|l|}{ Glucose $\mathrm{mg} \cdot \mathrm{dL}^{-1}$} \\
\hline Complicated & 1 & 5 & 36.5 & 65 & 147 & \\
\hline Noncomplicated & 57 & 97 & 127 & 135 & 374 & $<0.001$ \\
\hline \multicolumn{7}{|l|}{ Protein $\mathrm{g} \cdot \mathrm{dL}^{-1}$} \\
\hline Complicated & 3 & 3.3 & 4.4 & 5.6 & 7.3 & \\
\hline Noncomplicated & 3 & 3.2 & 3.8 & 4.7 & 6 & 0.026 \\
\hline \multicolumn{7}{|l|}{$\mathrm{LDH} \mathrm{IU} \cdot \mathrm{L}^{-1}$} \\
\hline Complicated & 159 & 1.37 & 8.22 & 6.91 & 50.0 & \\
\hline Noncomplicated & 153 & 323 & 539 & 708 & 1.74 & $<0.001$ \\
\hline \multicolumn{7}{|c|}{ Myeloperoxidase $\mu \mathrm{g} \cdot \mathrm{L}^{-1}$} \\
\hline Complicated & 745 & 15.0 & 99.0 & 5.50 & 625 & \\
\hline \multirow{2}{*}{\multicolumn{7}{|c|}{ Neutrophils $10^{3} \cdot \mu \mathrm{L}^{-1}$}} \\
\hline & & & & & & \\
\hline Complicated & 4.05 & 7.82 & 65.8 & 90.0 & 725 & \\
\hline Noncomplicated & 4.02 & 4.13 & 3.00 & 6.78 & 14.2 & $<0.001$ \\
\hline
\end{tabular}

Complicated: complicated paraneumonic pleural fluid $n=36$; Noncomplicated: noncomplicated paraneumonic pleural fluid $\mathrm{n}=34$; LDH: lactate dehydrogenase; P25: 25th percentile; P75: 75th percentile.

biochemical markers $\left(\mathrm{pH}<7.2\right.$ or glucose $<40 \mathrm{mg} \cdot \mathrm{dL}^{-1}$ or $\mathrm{LDH}>1,000 \mathrm{IU} \cdot \mathrm{L}^{-1}$ ) was $94 \%$, with a kappa value of 0.874 (SE was $0.070 ; \mathrm{p}<0.0001$ ).

Among the 36 PPE classified as complicated by the conventional biochemical criteria, $34(94 \%)$ had pleural $\mathrm{pH}<7.20$ or pleural glucose $<40 \mathrm{mg} \cdot \mathrm{dL}^{-1}$ or pleural $\mathrm{LDH}>1,000 \mathrm{IU} \cdot \mathrm{L}^{-1}$ and $\mathrm{MPO}>3.000 \mu \mathrm{g} \cdot \mathrm{L}^{-1}$ and none had $\mathrm{pH}<7.20$ and $\mathrm{MPO}<3.000 \mu \mathrm{g} \cdot \mathrm{L}^{-1}$. The other two complicated PPE were classified as such by positive pleural-fluid culture, with pleural $\mathrm{pH}>7.20$ and pleural $\mathrm{MPO}<3.000 \mu \mathrm{g} \cdot \mathrm{L}^{-1}$. Serratia marcescens and Crytococcus neoformans were isolated from pleural fluid in these patients.

In the 34 noncomplicated PPE, 28 (82\%) had a $\mathrm{pH}>7.20$ or glucose $>40 \mathrm{mg} \cdot \mathrm{dL}^{-1}$ or $\mathrm{LDH}<$ $1,000 \mathrm{IU} \cdot \mathrm{L}^{-1}$ and $\mathrm{MPO}<3.000 \mu \mathrm{g} \cdot \mathrm{L}^{-1}$. On the basis of

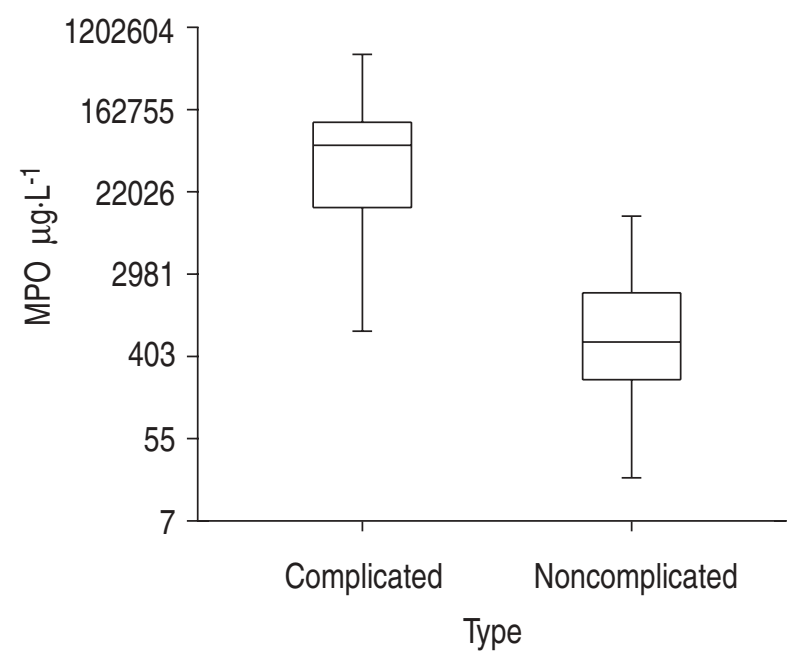

Fig. 1.-Pleural-fluid myeloperoxidase (MPO) distribution in the two types of pleural effusion (complicated and noncomplicated). The box and whisker represent median, interquartile range and complete range. biochemical criteria for classifying complicated PPE (pleural $\mathrm{pH}<7.20$ or pleural glucose $<40 \mathrm{mg} \cdot \mathrm{dL}^{-1}$ ), pleural MPO identified five more PPE as being complicated and four of these had pleural LDH> $1,000 \mathrm{IU} \cdot \mathrm{L}^{-1}$. Follow-up radiography on three of these five patients showed the presence of pleural thickening.

Associations between polymorphonuclear count and biochemical markers in pleural fluid and later loculation or pleural thickening were statistically significant for $\mathrm{pH}(\mathrm{p}=0.001)$, glucose $(\mathrm{p}=0.048)$, MPO $(\mathrm{p}=0.026)$ and polymorphonuclear leukocyte count $(\mathrm{p}=0.013)$.

\section{Discussion}

Several pleural-fluid measurements have been used to assess the severity and predict the course of

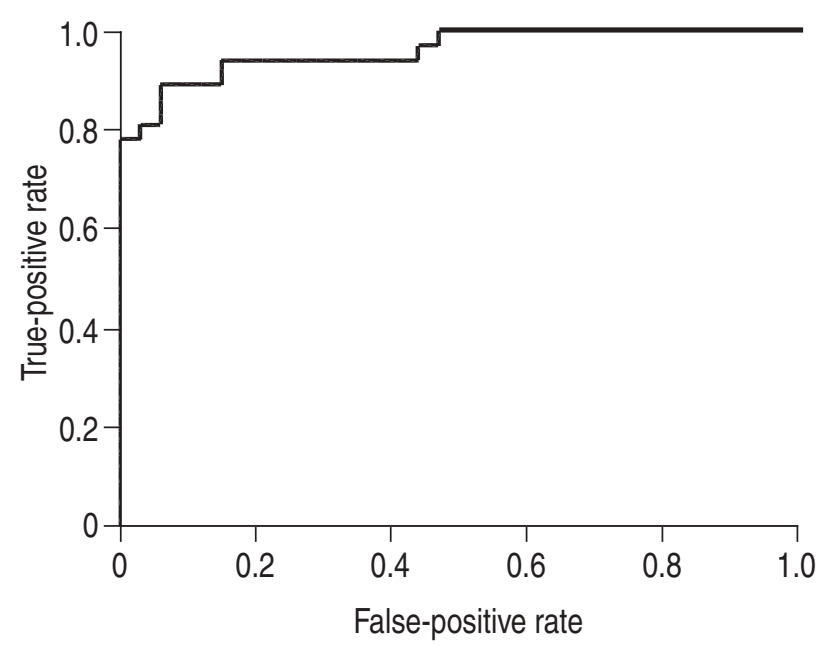

Fig. 2.- Receiver operating characteristic curve for predicting that a parapneumonic pleural effusion is or is not complicated, from a regression model with log pleural-fluid myeloperoxidase (area under the curve 0.969$)$. Cut-off $3.000 \mu \mathrm{g} \cdot \mathrm{L}^{-1}$. 


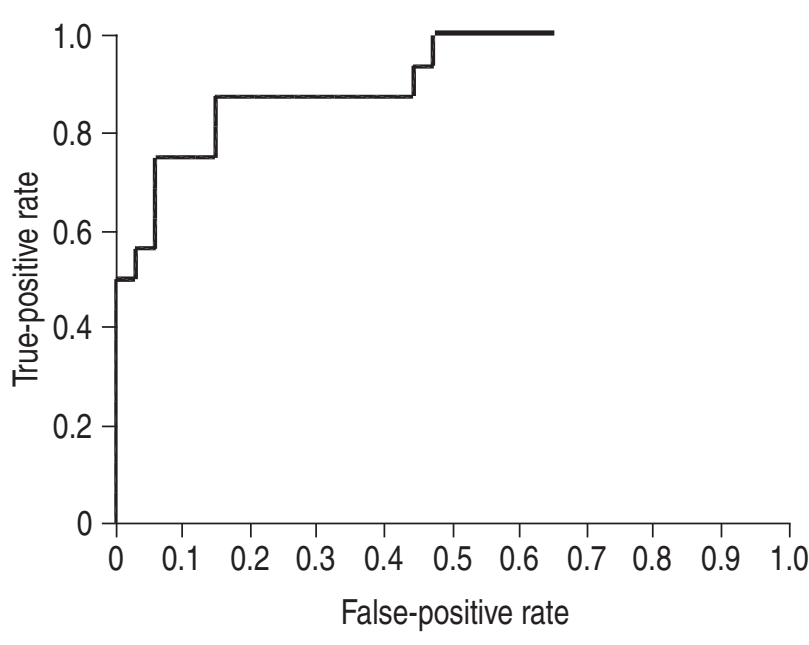

Fig. 3.-Receiver operating characteristic curve for predicting, after excluding purulent effusions, that a parapneumonic effusion is or is not complicated, from a regresion model with log pleuralfluid myeloperoxidase (area under the curve 0.912). Cut-off $3.000 \mu \mathrm{g} \cdot \mathrm{L}^{-1}$.

a parapneumonic effusion [21]. The duration and severity of pleural infection and the associated inflammatory response induce metabolic changes that alter pleural-fluid chemistry. Extensive intrapleural infections decrease $\mathrm{pH}$, lower glucose, and raise LDH values in pleural fluid [17]. Case series of patients with parapneumonic effusions suggest that these tests can discriminate between nonpurulent parapneumonic effusions that require drainage and those that will most likely respond to antibiotic therapy alone [17, 22, 23].

The biochemical characteristics of pleural fluid are the indices most often used to identify complicated $\mathrm{PPE}$, and $\mathrm{pH}$ is one of the most widely used guides to indicate the need for pleural drainage in this condition $[1,14,24,25]$. The importance of the combination of biochemical indices $\left(\mathrm{pH}<7.2\right.$, glucose $<40 \mathrm{mg} \cdot \mathrm{dL}^{-1}$, $\mathrm{LDH}>1,000 \mathrm{IU} \cdot \mathrm{L}^{-1}$ ) in the diagnosis of $\mathrm{PPE}$ has been stressed previously [3].

It is well recognized that accurate $\mathrm{pH}$ determination requires strict anaerobic extraction and rapid transport and analytical techniques. These conditions, however, are not always fulfilled [16]. Physicians handle samples for pleural-fluid $\mathrm{pH}$ determination in a variety of ways [26], such as collection in a large syringe and transfer to a heparinized syringe for $\mathrm{pH}$ assessment [27], and with varying use of local anaesthesia [28].

In a recently published meta-analysis investigating the ability of the commonly used markers to identify complicated PPE requiring drainage, the results for fluid $\mathrm{pH}$ showed an area under the ROC curve of 0.92 and, after excluding purulent effusions from the analysis, 0.89 . Pleural-fluid $\mathrm{pH}$ had a relatively high diagnostic accuracy, greater than that of pleuralfluid glucose and $\mathrm{LDH}$, for discriminating between complicated and noncomplicated parapneumonic effusions [21].

The present study identified pleural-fluid MPO, with a sensitivity of $94.1 \%$ and a specificity of $85.1 \%$ at the $3.000 \mu \mathrm{g} \cdot \mathrm{L}^{-1}$ cut-point, as the best index for discriminating between complicated and noncomplicated PPE. After excluding purulent effusions, pleural-fluid MPO was still the marker that best differentiated between the two types of PPE, with a sensitivity of $87.5 \%$ and a specificity of $85.1 \%$ at a cut-point limit of $3.000 \mu \mathrm{g} \cdot \mathrm{L}^{-1}$. The differences in mean levels of MPO between a previous report [13] and this study, are due to the inclusion of four additional cases in each subgroup of PPE. The aim of the previous report was to study whether interleukin (IL)- 8 was produced in the pleural space and its relation to the neutrophil activation state in infected pleural fluid.

It is recognized that during the inflammatory process, leukocytes release intracellular constituents, such as bactericidal permeability-increasing protein, defensins, lysozyme, cationic proteins, lactoferrin and zinc-binding proteins [9]. MPO is the most abundant protein of the neutrophils and catalyzes the conversion of hydrogen peroxide and chloride into hypochloride [29], an essential component of the oxygen-dependant microbicidal system, with NADPH oxidase of neutrophils and monocytes [30]. An increased MPO concentration is an indirect, but clear indication of MPO release by an inflammatory process. MPO, as a marker of inflammation, has been measured to distinguish otitis media, chronic sinusitis, chronic bronchitis and peritonitis of bacterial origin [10-12], in which excellent correlations have been observed with levels of IL-8, a cytokine involved not only in chemotaxis, but also in neutrophil activation.

The demonstration of the discriminatory role of pleural MPO, after excluding purulent PPE, together with the significant relations between pleural MPO and standard biochemical markers and between pleural levels of neutrophilic markers and pleural complications of PPE, suggest that MPO may be a useful tool for the management of patients with PPE. Correct differentiation between a complicated and noncomplicated PPE is associated with better prognosis [5]. Late pleural drainage can result in complications, leading to decreased pulmonary function. Moreover, there may be a greater need for pleural thrombolytic agents and pleural decortication $[4,5,15]$, implying increased hospital stay and healthcare costs [5].

Significant pleural complications still occur when using classical criteria to indicate pleural drainage, i.e. the presence of purulent pleural fluid, microorganisms on Gram-stain and/or positive culture andpleural $\mathrm{pH}<7.20$ and/or pleural glucose $<40 \mathrm{mg} \cdot 100 \mathrm{~mL}^{-1}$ in the context of a clinical and radiological process $[17$, 18]. There are three situations in which the usefulness of $\mathrm{pH}$ is subject to controversy: 1 ) in cases where $\mathrm{pH}$ is between 7-7.2, there is no consensus as to the ideal approach to take and opinions range from the use of conservative treatment, i.e. empirical therapy with broad-spectrum antibiotics, to early thoracic drainage; 2 ) in cases involving technical difficulties in the extraction, transport or processing of the samples; and 3) when the value of $\mathrm{pH}$ results is questionable because patients received antibiotic treatment before thoracocentesis. Determination of pleural-fluid MPO 
concentration could be particularly useful in these borderline or difficult cases. In the present study, measurement ofpleural MPO permitted early detection of five patients with complicated PPE, four of whom had pleural LDH $>1,000 \mathrm{IU} \cdot \mathrm{L}^{-1}$. Subsequently, complications consisting of pleural thickening were detected inthree of these patients and two of them also had pleural $\mathrm{LDH}>1,000 \mathrm{IU} \cdot \mathrm{L}^{-1}$. In addition, itwas found that the handling of samples was comparatively simple and did not require the strict conditions required for accurate $\mathrm{pH}$ determination [16, 26, 27].

The present results indicate that pleural-fluid myeloperoxidase concentration is a good discriminant between nonpurulent complicated and noncomplicated parapneumonic pleural fluid. Myeloperoxidase measurement could help in the management of this condition, since it is less affected by technical variation than $\mathrm{pH}$ determination. Pleural-fluid myeloperoxidase concentrations $>3.000 \mu \mathrm{g} \cdot \mathrm{L}^{-1}$ are highly suggestive of complicated parapneumonic pleural effusion.

Acknowledgements. The authors would like to thank C.L. Cavallo for linguistic advice.

\section{References}

1. Light RW, Girard EM, Jenkinson SG, et al. Parapneumonic effusions. Am J Med 1980; 69: 507-512.

2. Antony VB, Mohammed KA. Pathophysiology of pleural space infections. Sem Respir Infect 1999; 14: 9 17.

3. Light RW. A new classification of parapneumonic effusions and empyema. Chest 1995; 108: 299-301.

4. Heffner JE. Indications for draining a parapneumonic effusion: an evidence-based approach. Sem Respir Infect 1999; 14: 48-58.

5. Heffner JE, McDonald J, Barbieri C, et al. Management of parapneumonic effusions. An analysis of physician practice patterns. Arch Surg 1995; 130: 433438.

6. Lehrer RI, Ganz T, Selsted ME, Babior BM, Curnutte JE. Neutrophils and host defense. Ann Intern Med 1988; 109: 127-142.

7. Lonky SA, McCarren J. Neutrophil enzymes in the lung: regulation of neutrophil elastase. Am Rev Respir Dis 1983; 127: 9-15.

8. Alegre J, Suriñach JM, Varela E, et al. Diagnostic accuracy of pleural fluid polymorphonuclear elastase in the differentiation between pyogenic bacterial infectious and non-infectious pleural effusions. Respiration 2000; 67: 426-432.

9. Olsson I, Venge P. Cationic proteins of human granulocytes. Blood 1974; 44: 235-236.

10. Hurst DS, Venge P. Levels of eosinophil cationic protein and myeloperoxidase from chronic middle ear effusion in patients with allergy and/or acute infection. Otolaryngol Head Neck Surg 1996; 114: 531-544.

11. Demoly P, Crampette L, Mondain M, Enander I, Jones I, Bousquet J. Myeloperoxidase and interleukin-8 levels in chronic sinusitis. Clin Exp Allergy 1997; 27: 672-675.

12. Edelstam GA. Hyaluronan and myeloperoxidase in human peritoneal fluid during genital inflammation. Inflammation 1994; 18: 13-21.

13. Segura RM, Alegre J, Varela E, et al. Interleukin-8 and markers of neutrophil degranulation in pleural effusions. Am J Respir Crit Care Med 1998; 157: 15651572.

14. Potts DE, Levin DC, Sahn SA. Pleural fluid $\mathrm{pH}$ in parapneumonic pleural effusions. Chest 1976; 70: 328 331.

15. Hamm R, Light RW. Parapneumonic effusion and empyema. Eur Respir J 1997; 10: 1150-1156.

16. Cheng D, Rodriguez RM, Rogers J, Wagster M, Starnes DL, Light RW. Comparison of pleural fluid values obtained using blood gas machine, $\mathrm{pH}$ meter, and $\mathrm{pH}$ indicator Strip. Chest 1998; 114: 1368-1372.

17. Sahn SA. Management of complicated parapneumonic pleural effusions. Am Rev Respir Dis 1993; 148: 813-817.

18. Poe R, Marin M, Israel R, Kallay M. Utility of pleural fluid analysis in predicting tube thoracostomy decortication in parapneumonic pleural effusions. Chest 1991; 100: 963-967.

19. Hafner G, Dreher M, Lutgehaus M, et al. Determination of human granulocyte elastase by the immunoactivation method on the Hitachi 717 automated analyser. Eur J Clin Chem Biochem 1991; 29: 179-183.

20. The measure of interrater agreement. In: Fleiss JL, ed. Statistical Methods for Rates and Proportions. New York, John Wiley, 1981; pp. 212-236.

21. Heffner JE, Brown LK, Barbieri C, DeLeo JM. Pleural fluid chemical analysis in parapneumonic pleural effusions. A meta-analysis. Am J Respir Crit Care Med 1995; 151: 1700-1708.

22. Alfageme I, Muñoz F, Pena N. Empyema of the thorax in adults. Etiology, microbiology findings, and management. Chest 1993; 103: 839-843.

23. Light RW. Management of parapneumonic effusions. Chest 1991; 100: 892-893.

24. Light RW, MacGregor MI, Ball WC, Luchsinger PC. Diagnostic significance of pleural fluid $\mathrm{pH}$ and $\mathrm{pCO} 2$. Chest 1973; 64: 591-596.

25. Light RW. Management of parapneumonic pleural effusions. Arch Intern Med 1981; 141: 1339-1341.

26. Byrd RP Jr, Roy TM, Quillen JH. Pleural fluid pH determination. Chest 1998; 113: 1426-1427.

27. Goldstein LS, McCarthy K, Mehta AC. Is direct collection of pleural fluid into a heparinized syringe important for determination of pleural $\mathrm{pH}$ ? Chest 1997; 112: 707-708.

28. Castro Jimenez D, Diaz G, Perez-Rodriguez E, Prieto $\mathrm{E}$, Yusen RD. Modification of pleural fluid $\mathrm{pH}$ by local anesthesia. Chest 1999; 116: 399-402.

29. Miyasaki KT, Song J, Murthy ARK. Secretion of myeloperoxidase isoforms by human neutrophils. Anal Biochem 1991; 193: 38-44.

30. Pabst MJ, Hedegaard HB, Johnston RBJ. Cultured human monocytes require exposure to bacterial products to maintain an optimal oxygen radical response. J Immunol 1982; 128: 123-128. 